\title{
元素分析計-同位体比質量分析計による有機物試料の 炭素・窒素・酸素安定同位体比分析の試験所間比較
}

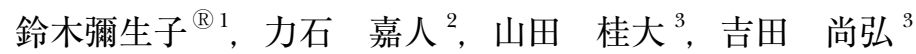

\section{1 背景及び目的}

軽元素（水素・炭素・窒素・酸素・硫黄）の安定同位体 比は, 関与する物理化学・化学・生化学反応によって変動 する. すなわち, その差（変動）には，起源物質と反応過 程・反応量が記録されているということであり，それを測 定することで, 物質循環の解明や食物網の構造解析, 動物 の食性解析といった地球化学・生態学・環境化学・考古学 などの分野の様々な研究課題を解くことができる ${ }^{1) \sim 3)}$. ま た特に近年では, この起源を推定する能力が, 食品の表示 偽装に対する科学的技術の一つとして注目を集めている. そのため, 安定同位体比分析は, 近年の測定技術の発展と 食品分野を中心とした社会的な需要の高まりを背景に，大 学・研究機関のみならず，民間企業においても使われ始め

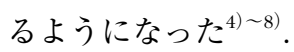

一方で, 留意すべき問題点として, 分析法の標準化が遅 れ, 妥当性確認が十分に行われていないことが挙げられ る. 安定同位体比は標準物質を基準とした相対值で示すこ とから, 測定条件 [燃焼・熱分解温度やガスクロマトグラ フ $(\mathrm{GC})$ カラム, 標準ガスと試料のピークの大きさの相 違, Heによる希釈率など]や標準物質による測定值の補 正方法が, 測定值の安定性・真度・精度に影響を及ぼすた め, 得られた測定値を常に注意媣く管理する必要があ $3^{910)}$ ．特に酸素同位体比については，未成熟な分析技術 を使用する上での留意点が多く, 国際的な専門誌に発表さ れた論文であっても，正しい測定法で正しい結果を報告し ているとは言い難いものも少なくない ${ }^{10)}$. 恣意的かどうか は別として，国内においても，これらの分析における留意 点を十分に把握できずに分析を進める機関も，残念ながら 存在していると考えられる.

このような状況下にもかかわらず，産地判別など産業技

\footnotetext{
${ }^{\circledR}$ E-mail : yaekos@affrc.go.jp

1 独立行政法人農業・食品産業技術総合研究機構 食品総合研究所 食品分析研究領域：305-8642 茨城県つくば市観音台 2-1-12

2 独立行政法人海洋研究開発機構 海洋 - 極限環境生物圈領域: 237-0061 神奈川県横須賀市夏島町 2-15

3 東京工業大学大学院総合理工学研究科化学環境学専攻 : 2268502 神奈川県横浜市緑区長津田町 4259G1-17
}

術への応用が注目され，新聞記事などの報道で取り挙げら れている，安定同位体比の持つ有用性・可能性を最大限引 き出すためには, 標準物質の整備, 妥当性確認の実施, 標 準的な分析手法の整備と各研究室におけるその準拠などが 求められている.

本研究では，日本国内に扔ける安定同位体比分析技術の 現状把握を目的とし，表示・起源分析技術研究懇談会の事 業として, 炭素・窒素・酸素安定同位体比の室間試験を実 施した.

\section{2 試料及び分析方法}

\section{$2 \cdot 1$ 試験用標品}

表示・起源分析技術研究㼡談会より試験用の標品を配付 し，測定値を集計した。炭素同位体比 $\left(\delta^{13} \mathrm{C}\right)$ 及び窒素同 位体比 $\left(\delta^{15} \mathrm{~N}\right)$ 測定用には, L-phenylalanine（和光純薬工 業製, 純度 $99+\%$ ， ロット番号 CDH6490）（Fig. 1a）を 選定し， $\delta^{13} \mathrm{C}$ はのべ 25 機関， $\delta^{15} \mathrm{~N}$ はのべ 22 機関にて分析 を行った. 酸素同位体比 $\left(\delta^{18} \mathrm{O}\right)$ 測定用には, 窒素を含まな い化合物として 1,2,3,4,6-penta- $O$-acetyl- $\alpha$-D-glucopyranose (和光純薬工業製，純度 $97+\% ，$ ロット番号 EWG0849) (Fig. 1b), 窒素含む化合物として Dimethyl aminoterephthalate (Aldrich 製, 97+ \%, ロット番号 8.18675.0050) （Fig. 1c）を標品として選定した．前者はのべ 12 機関，後 者はのべ 8 機関にて分析を行った. $\delta^{18} \mathrm{O}$ の測定では，熱分 解過程に扔いて酸素分が $\mathrm{CO}$ ガスに変換されるが, 窒素分 も $\mathrm{N}_{2}$ ガスに変換される. $\mathrm{CO}$ ガスは $m / z 28$ であり, $\mathrm{N}_{2}$ ガ スも $m / z 28$ であるため, $\mathrm{CO}$ ガスと $\mathrm{N}_{2}$ ガスの分離が真度 へ大きな影響を及ぼすと考えられることから 2 種類を選定 した.

\section{$2 \cdot 2$ 分析方法}

安定同位体比分析には，Dual Inlet タイプの同位体比質 量分析計（IRMS）で安定同位体比を測定する方法と，前処 理装置と IRMS をオンラインでつなぐ連続フロー(continuous-flow）タイプの測定機器を使用する方法がある. 今回 は, 後者のオンライン測定機器を対象とし, $\delta^{13} \mathrm{C}, \delta^{15} \mathrm{~N}$ は, 元素分析計-同位体比質量分析計 (EA-IRMS), 酸素同位体 
(a)

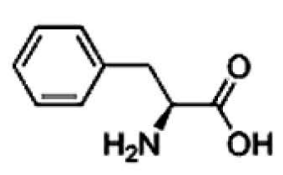

(b)

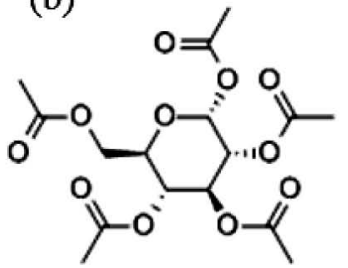

(c)

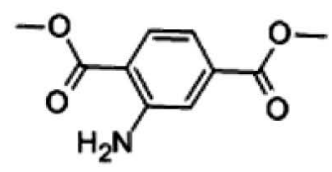

Fig. 1 Three organic compounds distributed for the inter-laboratory test

(a) L-alanine for $\delta^{13} \mathrm{C}$ and $\delta^{15} \mathrm{~N}$ measurements ; (b) 1,2,3,4,6-penta-O-acetyl- $\alpha$-D-glucopyranose for $\delta^{18} \mathrm{O}$ measurements ; (c) Dimethyl aminoterephthalate for $\delta^{18} \mathrm{O}$ measurements

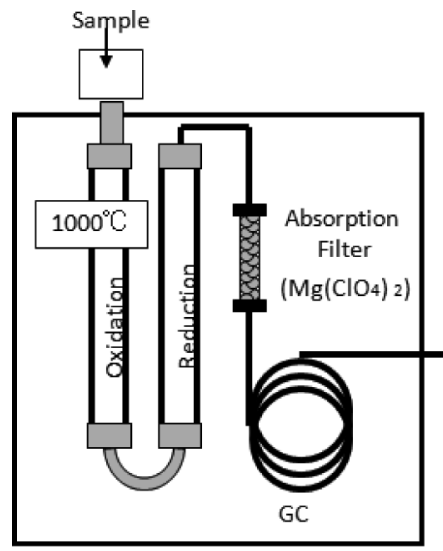

Elemental Analyzer(EA)

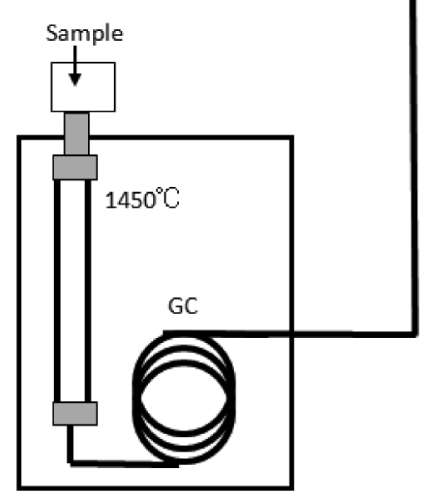

Thermal Conversion Elemental Analyzer(TCEA)

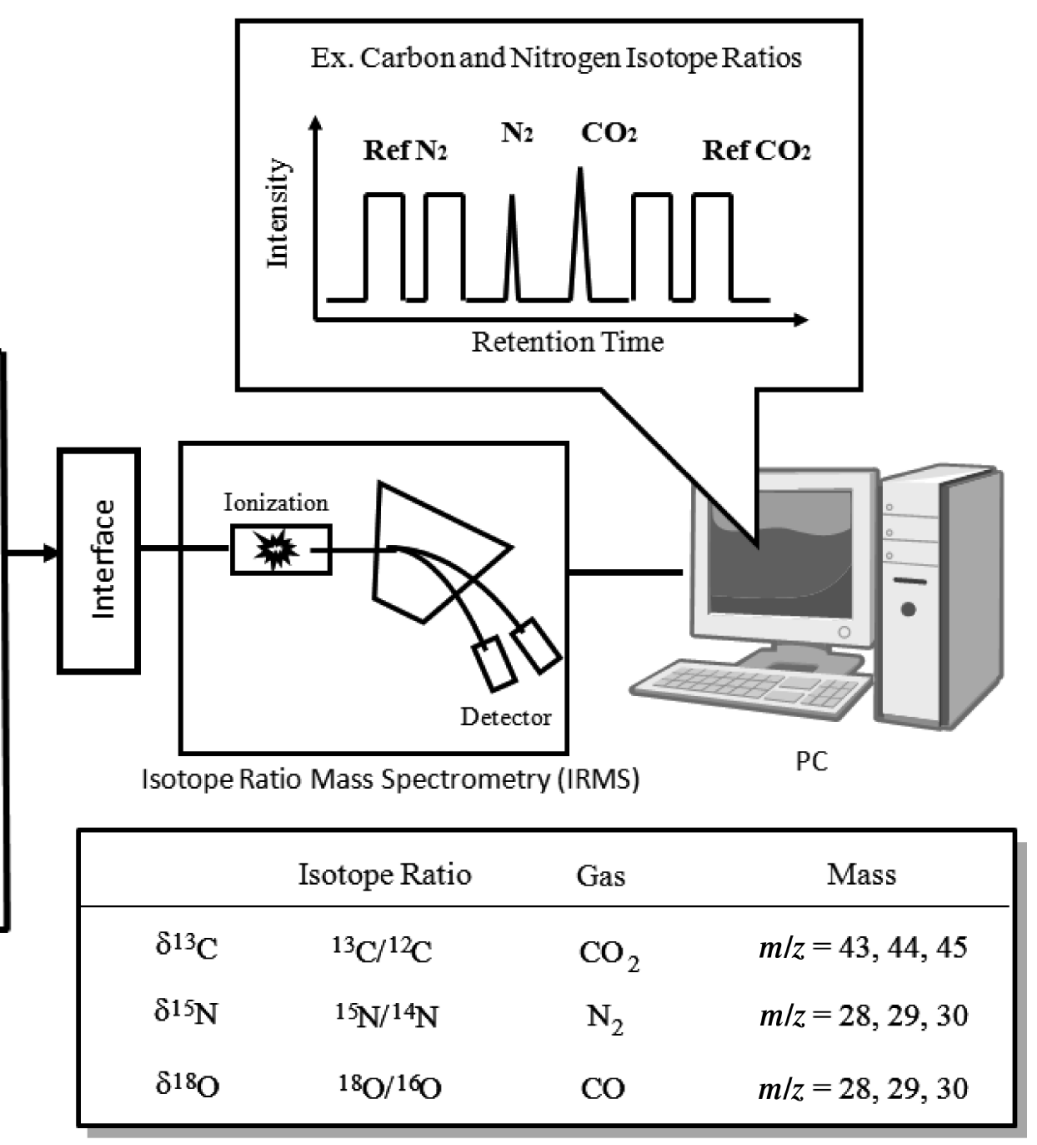

Fig. 2 Schematic layout of the elemental analyzer-isotope ratio mass spectrometer (EA-IRMS) and the thermal conversion elemental analyzer-isotope ratio mass spectrometer (TCEA-IRMS) system

比は，熱分解型元素分析計-同位体比質量分析計（TCEAIRMS）を用いて分析を行うことを条件とした（Fig. 2).使 用機器の機種やメーカーは任意とした。

各研究室には, 各試料が $1 \mathrm{~g}$ 程度入ったバイヤルを配付 した. 各試料の反復測定数は $N=3$ とし, 平均値 \pm 標準偏 差 $(1 \sigma)$ の報告を求めた，それぞれの元素の安定同位体比 は, $\delta X=\left(R_{\text {誡衼 }} / R_{\text {標染 }}-1\right) \times 1000$ によって,$\delta$ 値としての 報告とした， $X$ は, 炭素, 窒素, 酸素に対して, それぞれ ${ }^{13} \mathrm{C},{ }^{15} \mathrm{~N},{ }^{18} \mathrm{O}$ を表し， $R$ はそれぞれの元素の同位体比 ${ }^{13} \mathrm{C} /{ }^{12} \mathrm{C},{ }^{15} \mathrm{~N} /{ }^{14} \mathrm{~N},{ }^{18} \mathrm{O} /{ }^{16} \mathrm{O}$ である。また, 国際スタンダー
ドスケールとして, 炭素では PeeDee 層のヤイシ類の化石 (V-PDB), 窒素では大気窒素 (Air), 酸素は標準平均海水 （V-SMOW）スケールでの報告とした．使用する標準物質 (reference materials), 作業標準物質 (working standards), 補正方法については, 任意で行った，参加機関は，表示・ 起源分析技術研究懇談会の電子メールで募り, 大学, 研究 機関，民間企業を合わせたのべ 25 機関の参加となった.

\section{3 結果と考察}

各参加機関の報告值の平均值と標準偏差を Fig. 3 及び 

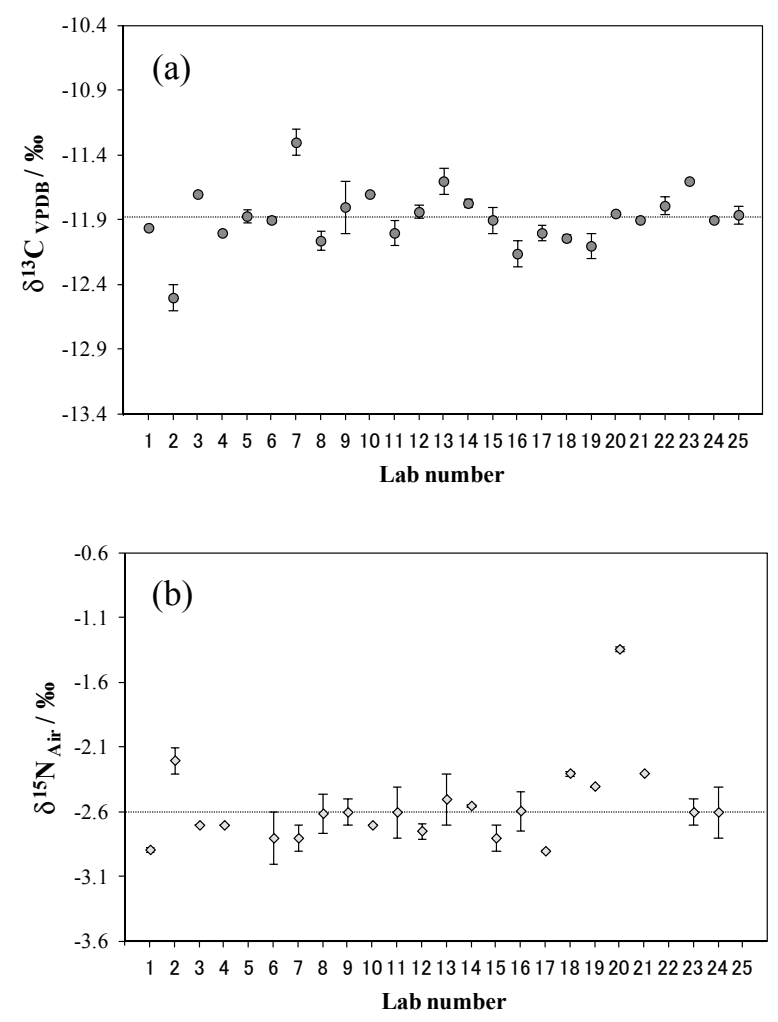

Fig. 3 Analytical results of (a) $\delta^{13} \mathrm{C}$ (25 laboratories) and (b) $\delta^{15} \mathrm{~N}$ measurements (22 laboratories) for L-alanine

The dotted line shows the average of all participating laboratories. The error bars show the $1 \sigma$ standard deviation of each participating laboratory.

Fig. 4 に示す. 図中の点線は参加機関の平均值を示し, 各

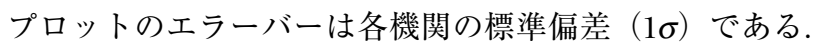

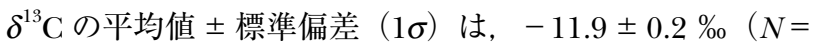
25） (Fig. 3a), $\delta^{15} \mathrm{~N}$ の平均值 \pm 標準偏差 $(1 \sigma)$ は, -2.6 $\pm 0.3 \%$ \% $\left(N=22 ）\right.$ (Fig. $3 \mathrm{~b} ）$ であった. $\delta^{18} \mathrm{O}$ の平均值 \pm 標準偏差 $(1 \sigma)$ は, 窒素を含まない 1,2,3,4,6-penta- $O$-acetyl$\alpha$-D-glucopyranose $か ゙+32.3 \pm 1.0 \%(N=12 ） \quad($ Fig. 4a) , 窒素を含む Dimethyl aminoterephthalate が+ $25.9 \pm 2.3 \%$ $(N=8)$ となった（Fig. 4b).

一方で, 各元素の安定同位体比の室間差を良く見ると, $\delta^{13} \mathrm{C}$ は最大で $1.2 \%$ （最小值：-12.5, 最大值 : $-11.3 \%$ ), $\delta^{15} \mathrm{~N}$ は最大で $1.6 \%$ (最小值 : -1.3 , 最大值 : $-2.9 \%$ o) であるのに対し, $\delta^{18} \mathrm{O}$ は室間差が大きく, 窒素 を含まない 1,2,3,4,6-penta- $O$-acetyl- $\alpha$-D-glucopyranose は, 最大で $3.7 \%$ （最小值： +31.2 , 最大值 : + $34.9 \%$ ）, 窒 素を含む Dimethyl aminoterephthalateにおいては, 最大で $7.4 \%$ （最小值 : + 21.9, 最大值 : + $29.3 \%$ ）の室間差と なった.

炭素・窒素・酸素同位体比分析に共通した課題として は，安定同位体比の補正方法が標準化されていないことが
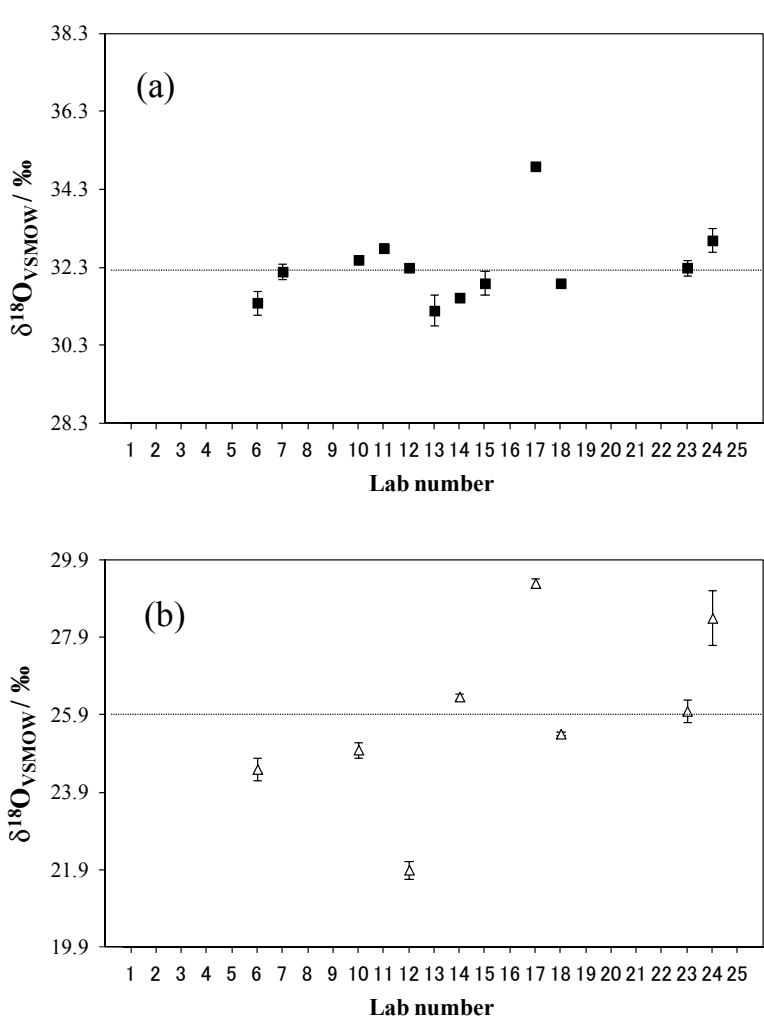

Fig. 4 Analytical results of $\delta^{18} \mathrm{O}$ measurements for (a) 1,2,3,4,6-penta- $O$-acetyl- $\alpha$-D-glucopyranose (12 laboratories) and (b) Dimethyl aminoterephthalate (8 laboratories)

The dotted line shows the average of all participating laboratories. The error bars show the $1 \sigma$ standard deviation of each participating laboratory.

挙げられる．参加機関からのアンケートでは，標準ガスの 值を決めて補正する方法もあれば，一つの作業標準物質で 補正する方法, 複数の作業標準物質で補正する方法など, 各機関によって様々であった，推奨法としては，值の異な る複数 $(4 \sim 6$ 種類 $)$ の有機物を作業標準物質として用い, 補正を行う方法を挙げる ${ }^{910)}$. 測定の際に基準とする標準 ガスの同位体比を $0 \%$ として仮定し, 得られた測定值 （ $\boldsymbol{\delta}$ vs. ref.gas）に対して真值（ $\delta$ vs. ref.gas）をとり，補正 式を作成する，推奨法により，以下の三つの利点が得られ る.

（1）燃焼や熱分解などに伴う装置内部での同位体分別 や, IRMS 固有の特徴として真值/測定值の傾きが 1.0 にな らない問題などを相殺することとなり，安定した測定が可 能となる。

（2）補正式の相関係数を確認することにより，その日の 装置の状態を確認することができる.

（3）個々の作業標準物質に含まれる誤差（偶然誤差）を 平均化し, 系統誤差を小さくすることが可能となる.

実試料の測定を行う際は，10〜 12 試料ごとに作業標準 物質を組み込み, 測定值のチェックや補正式の更新を行う 
ことで, 試料の測定を積み重ねることによる燃焼率や熱分 解効率の変動など装置の条件の変化に対応した精度管理を 行うことも必要である.

一方で, $\delta^{13} \mathrm{C} \cdot \delta^{15} \mathrm{~N}$ に比べて, $\delta^{18} \mathrm{O}$ の室間差が大きい. 主な理由として, 窒素ピークの酸素同位体比への影響が挙 げられる，酸素同位体比を測定する際は，有機物を高温で 熱分解し, 酸素を一酸化炭素 $(\mathrm{CO})$ ガスに変換した後, 同 位体比質量分析計（IRMS）で酸素同位体比を測定する. 生 物試料中には一般的に窒素が含まれるため, 熱分解過程に おいて窒素分が窒素 $\left(\mathrm{N}_{2}\right)$ ガスに変換される. $\mathrm{N}_{2}$ ガスは $m / z 28$ であり, CO ガスも $m / z 28$ であるため, CO ガス と $\mathrm{N}_{2}$ ガスの分離に十分かつ細心の注意が必要となる. $\mathrm{N}_{2}$ ピークと CO ピークの分離が十分でないと, CO の酸素同 位体比が大きく変動する ${ }^{10) 1415)}$. Brand らでは, ドイツが 中心となり, アメリカ・オランダ・オーストリア・スイス の研究機関が参加して, オンライン法を用いた酸素同位体 比の室間試験が報告されている ${ }^{14)}$. 有機物としては, 安息 香酸（IAEA-601 及びIAEA-602） とともに, カフェイン (IAEA-600) についても室間試験が行われている，窒素を 含まない安息香酸では，+71.06〜+72.05\% と安定した 值を示しているが, 窒素含有化合物であるカフェインの結 果では, $-3.29 \sim-12.63 \%$ となり, 試験室間の平均值が $9 \%$ も異なり, さらに試験室内偏差も最大で $4.2 \%$ と報告 されている. クロマトグラフ上でピークが分かれているよ うに見えても， $\mathrm{N}_{2}$ ピークの尾（テーリング）がバックグラ ンドまで下がりきらずに, CO ピークへ干渉する可能性が ある.Qiらでは, アメリカ地質調查所 (United States Geological Survey, USGS）が販売しているヒトの毛髮の標 準物質である USGS42 及び USGS43 を用いて, 酸素同位体 比分析の検証を行っている ${ }^{15)}$. 装置購入時に付属している GC カラムの長さは $0.6 \mathrm{~m}$ であるが, GC カラムの長さを $1.0 \sim 1.5 \mathrm{~m}$ にすることで $\mathrm{N}_{2}$ ピークと CO ピークの分離が 改善され, 比較的安定して酸素同位体比を測定できること が述べられている，また，カラムを長くしただけでは， $\mathrm{N}_{2}$ ピークのテーリングの干渉は完全には改善されず, ヘリウ ムガスによって, $\mathrm{N}_{2}$ ピークを希釈することで, イオン源へ の窒素ピークの影響を抑えることにより, さらに安定した 值が得られることも示されている.

分析の信頼性向上に向けて, 上述の測定值の補正方法や 測定条件などの分析方法の留意点に加えて, 標準物質や作 業標準物質の選定においても注意が必要である. 安定同位 体比を測定するには, 測定したい元素の安定同位体比が決 められた標準物質を用いて補正を行う必要がある。一次標 準物質または二次標準物質として, 国際原子力機構 (International Atomic Energy Agency： IAEA）などによっ て製造・供給されている国際規格の安定同位体標準物質が あり, 水・無機物・有機物などさまざまな構造や数值のも
のを購入することが可能である ${ }^{11)}$. 有機物の炭素・窒素同 位体比に関しては, 比較的標準物質が充実しており, IAEA 等から購入可能な標準物質としてもアミノ酸・カフェイ ン・セルロース・スクロースなどがあり, 数值も幅広くそ ろっている. 一方, 購入可能な酸素同位体比の標準物質と しては, 水や無機物は比較的充実しているが, 有機物とし ては安息香酸のみであり, 数值も+71.28 $\pm 0.36 \%$ （IAEA-

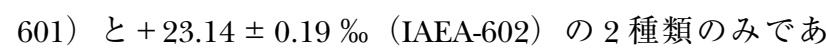
る. 自然界の植物 ・動物試料の酸素同位体比は, $+10 \sim$ + $40 \%$ \% であるので, 今後, これらの範囲を考慮した標準 物質を整備することが急務である. 2012 年に入り, Coplen らによって, 毛髪の炭素・窒素・酸素・水素・硫黄同位体 比が報告されている. USGS42 はチベット人の毛髪, USGS43 はインド人の毛髪であり, 各試料の酸素同位体比 は， $+8.56 \pm 0.10 \%$ o $(N=18 ）$ と + $14.11 \pm 0.10 \% （ N=$ 18）と報告されている ${ }^{12)}$. USGSより販売されていること から, 今後の標準物質の整備において重要な標準物質と考 えられる ${ }^{13)}$.

IAEA より販売されている標準物質は, 有機物・無機物 では $0.5 \mathrm{mg}$ 前後と少量であり, 価格も50000 円前後と高 価であることからこれらの標準物質を日々の測定に使用す ることは難しい. また, IAEA が定める購入制限により, 同 じユーザーは一度購入した製品を 3 年間購入することがで きない.よって，日々の測定には IAEAの標準物質を用い て，作業標準物質を作製する必要がある．作業標準物質を 作製する際には，測定対象物質に近い構造の試料を選択す ることが望ましい，例えば，有機物を測定する際に，無機 物のスタンダードを用いると, 燃焼効率や熱分解効率など が異なる可能性がある. 今回配付した試験用の標品は, 有 機物であることから，本来，有機物の標準物質を用いて補 正を行うことが望ましい. また，作業標準物質の数值の範 囲が, 測定対象試料の数值の範囲をカバーできるように, 作業標準物質を選定することも重要である. 有機物の炭 素・窒素同位体比分析においては，作業標準物質としてア ミノ酸を使用することが多い. 安定しており，長期保管が 可能なことや，様々なアミノ酸分子が存在することから数 值のバリエーションをそろえやすいことも利点と言える. 実際に, インディアナ大学や SI サイエンス(株などが作業標 準物質用として, バリエーション豊かな数值のアミノ酸を 販売していることから, 炭素・窒素同位体比の作業標準物 質は入手しやすい. 一方で, 酸素同位体比については, 保 管中の水蒸気の影響などが懸念されることから，吸湿性の ある化合物や, 交換性の高い酸素を持つ官能基 $(-\mathrm{OH}$, $-\mathrm{COOH},-\mathrm{COOR}$ など）が含まれる化合物を選定すると， 保管中に值が変化する可能性があり, 作業標準物質として 適さない. 残念ながら酸素を含む有機化合物のほとんど は, 吸湿性を持ち, またこれらの官能基を持つので, 酸素 
については，作業標準物質を選定する際にも問題が多いの が現状である。現状では，スタンダードとして入手可能な 有機物質は安息香酸のみであるが，しかし，安息香酸はカ ルボキシル基（-COOH）を持っているので, 酸素同位体 比の測定においては, 標準物質の整備も今後の大きな課題 である。

$$
4 \text { 結 言 }
$$

炭素・窒素・酸素安定同位体比について, 有機化合物を 用いた室間試験を実施した。炭素・窒素同位体比の室間差 は, $1.2 \%$ と $1.6 \%$ となり, 比較的正しく測定されている 結果となったが, 酸素同位体比については最大で $7.4 \%$ の 室間差があることが分かり，これは今後の標準物質及び標 準分析法の整備により改善されるべきものと考えられる. 現在, 有機物の安定同位体比測定用の標準物質を拡充・整 備する国際的なプロジェクトが進行しており（日本では海 洋研究開発機構が参加), その成果も期待される. 国内にお いても, 今後の対策として, 測定条件や測定值の補正方法 の標準化, 標準物質の整備, 定期的な室間試験の実施を行 いながら, 分析法の信頼性を確保するとともに, プロト コールの作成を行うことが急務である，また，本試験は一 般試薬を標品として実施したが, 最終的にはマトリックス 試料を用いた室間試験の実施も必要である。いつでも, 誰 でも, 決められた方法に従って分析することで同じ結果が 得られるように, 講習会なども視野に入れながら分析法や 標準物質, 作業標準物質の整備を進めていく必要がある.

\section{5 謝 辞}

本室間試験は, 日本分析化学会表示・起源分析技術研究 懇談会の事業として行われたものである. 本試験に参加し て頂いた研究室・機関, 実施また結果の公表等において 様々なアドバイスを頂いた表示・起源分析技術研究懇談会 運営委員会に感謝する。

\section{文献}

1) 和田英太郎：日本生態学会誌, 59, 259 (2009).

2) B. Fry: "Stable Isotope Ecology", (2008), (SpringerVerlag, New York).

3) K. A. Hobson, L. I. Wassenaar (Ed.) : “Tracking Animal Migration with Stable Isotopes, Volume 2 (Terrestrial Ecology)", (2008), (Academic Press, city).

4) S. Kelly, K. Heaton, J. Hoogewerff : Trends Food Sci. Technol., 16, 555 (2005).

5) A. Gonzalvez, S. Armenta, M. de la Guardia : Trends Anal. Chem., 28, 1295 (2009).

6) Y. Suzuki, Y. Chikaraishi, N. Ogawa, N. Ohkouchi, T. Korenaga : Food Chem., 109, 470 (2008).

7) R. Hattori, K. Yamada, H. Shibata, S. Hirano, O. Tajima, N. Yoshida: J. Agric. Food Chem., 58, 7115 (2010)

8) 鈴木彌生子：食品衛生学雑誌, 52, 235 (2011).

9) 佐藤里恵, 鈴木彌生子：Res. Org. Geochem., 26, 21 (2010).

10) 鈴木彌生子, 佐藤里恵 : Res. Org. Geochem., 26, 31 (2010).

11) Reference Material Online Catalog, International Atomic Energy Agency (IAEA) Home Page (2012) : <http://nucleus.iaea.org/rpst/ReferenceProducts/ ReferenceMaterials/Stable_Isotopes/index.htm $>$.

12) T. B. Coplen, H. Qi : Forensic Sci. Int., 214, 135 (2012).

13) United States Geological Survey (USGS) Reston Stable Isotope Laboratory Home Page (2012): $<$ http://isotopes.usgs.gov/lab/referencematerials. html $>$.

14) W. A. Brand, T. B. Coplen, A. T. Aerts-Bijma, J. K. Böhlke, M. Gehre, H. Geilmann, M. Gröning, H. G. Jansen, H. A. J. Meijer, S. J. Mroczkowski, H. Qi, K. Soergel, H. S. Williams, S. M. Weise, R. A. Werner : Rapid Commun. Mass Spectrom., 23, 999 (2009).

15) H. Qi, T. B. Coplen, L. I. Wassenaar: Rapid Commun. Mass Spectrom., 25, 2049 (2011). 


\title{
Interlaboratory Comparison of Carbon, Nitrogen, and Oxygen Isotope Ratios in
}

\section{Organic Chemicals Using Elemental Analyzer-Isotope Ratio Mass Spectrometer}

\author{
Yaeko SuZuki $^{\circledR 1}$, Yoshito ChIKARAISHI ${ }^{2}$, Keita YAMAdA ${ }^{3}$ and Naohiro YoshidA ${ }^{3}$ \\ ${ }^{\circledR}$ E-mail : yaekos@affrc.go.jp
}

\footnotetext{
${ }^{1}$ Analytical Science Division, National Food Research Institute, 2-1-12, Kannondai, Tsukuba-shi, Ibaraki, 3058642

${ }^{2}$ Institute of Biogeosciences, Japan Agency for Marine-Earth Science and Technology, 2-15, Natsushima-cho, Yokosuka-shi, Kanagawa 237-0061

${ }^{3}$ Interdisplinary Graduate School of Science and Engineering Tokyo Institute of Technology, G1-17, 4259, Natatsuda, Midori-ku, Yokohama-shi, Kanagawa 226-8502
}

(Received April 2, 2012 ; Accepted May 25, 2012)

The elemental analyzer-isotope ratio mass spectrometer (EA-IRMS) has become increasingly important as a potential powerful tool for food authenticity. However, the lack of a reliable technique for the isotope ratio measurement, and limited availability of adequate international references are significantly regrettable, and should be improved immediately. Here we present results of an inter-laboratory test on the EA-IRMS determination of stable carbon, nitrogen and oxygen isotopic compositions $\left(\delta^{13} \mathrm{C}, \delta^{15} \mathrm{~N}\right.$ and $\left.\delta^{18} \mathrm{O}\right)$ in organic compounds. Three organic compounds (L-alanine for $\delta^{13} \mathrm{C}$ and $\delta^{15} \mathrm{~N}$, and 1,2,3,4,6-penta- $O$-acetyl- $\alpha$-Dglucopyranose and Dimethyl aminoterephthalate for $\delta^{18} \mathrm{O}$ ) were distributed and analyzed by a total of 25 laboratories. The results show that the $1 \sigma$ standard deviation among laboratories is $-11.9 \pm 0.2 \%$ (for $\left.\delta^{13} \mathrm{C}\right), \quad-2.6 \pm 0.3 \%$ o (for $\left.\delta^{15} \mathrm{~N}\right),+32.3 \pm 1.0 \%$ (for $\delta^{18} \mathrm{O}$ of the glucopyranose derivative), and $+25.9 \pm 2.3 \%$ (for $\delta^{18} \mathrm{O}$ of Dimethyl aminoterephthalate). Although the variations of the standard deviations for $\delta^{13} \mathrm{C}, \delta^{15} \mathrm{~N}$ and $\delta^{18} \mathrm{O}$ (glucopyranose derivative) among laboratories are not so large compared to the instrument uncertainties, $\delta^{18} \mathrm{O}$ of Dimethyl aminoterephthalate, which contains nitrogen, shows a large variation among laboratories. This may have been caused by much contamination of $\mathrm{N}_{2}$ to the $\mathrm{CO}$ peak on the EA-IRMS chromatogram, and may be improved by using a longer GC column $(1.0 \sim 1.5 \mathrm{~m})$ for chromatographic separation.

Keywords : stable isotope analysis ; inter-laboratory comparison ; $\delta^{13} \mathrm{C}$ value $; \delta^{15} \mathrm{~N}$ value $; \delta^{18} \mathrm{O}$ value. 